OPEN ACCESS

Edited by:

Jiantao Guo,

University of Nebraska-Lincoln,

United States

Reviewed by:

Sam Mathew,

University of Edinburgh,

United Kingdom

Francesca Paradisi,

University of Bern, Switzerland

${ }^{*}$ Correspondence:

Hyungdon Yun

hyungdon@konkuk.ac.kr

Specialty section:

This article was submitted to

Chemical Biology,

a section of the journal

Frontiers in Chemistry

Received: 20 December 2021 Accepted: 07 February 2022 Published: 28 February 2022

Citation:

Pagar AD, Jeon H, Khobragade TP, Sarak S, Giri P, Lim S, Yoo TH, Ko BJ and Yun $H$ (2022) Non-Canonical Amino Acid-Based Engineering of (R)Amine Transaminase.

Front. Chem. 10:839636. doi: 10.3389/fchem.2022.839636

\section{Non-Canonical Amino Acid-Based Engineering of $(R)$-Amine Transaminase}

\author{
Amol D. Pagar ${ }^{1}$, Hyunwoo Jeon ${ }^{1}$, Taresh P. Khobragade ${ }^{1}$, Sharad Sarak ${ }^{1}$, Pritam Giri ${ }^{1}$, \\ Seonga Lim ${ }^{1}$, Tae Hyeon $\mathrm{Yoo}^{2}$, Byoung Joon $\mathrm{Ko}^{3}$ and Hyungdon Yun ${ }^{1 *}$ \\ ${ }^{1}$ Department of Systems Biotechnology, Konkuk University, Seoul, South Korea, ${ }^{2}$ Department of Molecular Science and \\ Technology, Ajou University, Suwon, South Korea, ${ }^{3}$ School of Biopharmaceutical and Medical Sciences, Sungshin Women's \\ University, Seoul, South Korea
}

Non-canonical amino acids (ncAAs) have been utilized as an invaluable tool for modulating the active site of the enzymes, probing the complex enzyme mechanisms, improving catalytic activity, and designing new to nature enzymes. Here, we report site-specific incorporation of $p$-benzoyl phenylalanine $(\mathrm{pBpA})$ to engineer $(R)$-amine transaminase previously created from D-amino acid aminotransferase scaffold. Replacement of the single Phe88 residue at the active site with pBpA exhibits a significant 15-fold and 8-fold enhancement in activity for 1-phenylpropan-1-amine and benzaldehyde, respectively. Reshaping of the enzyme's active site afforded an another variant F86A/F88pBpA, with $30 \%$ higher thermostability at $55^{\circ} \mathrm{C}$ without affecting parent enzyme activity. Moreover, various racemic amines were successfully resolved by transaminase variants into $(S)$ amines with excellent conversions ( 50\%) and enantiomeric excess (>99\%) using pyruvate as an amino acceptor. Additionally, kinetic resolution of the 1-phenylpropan-1-amine was performed using benzaldehyde as an amino acceptor, which is cheaper than pyruvate. Our results highlight the utility of ncAAs for designing enzymes with enhanced functionality beyond the limit of 20 canonical amino acids.

\footnotetext{
Keywords: $(R)$-amine transaminase, genetic code expansion, enzyme engineering, non-canonical amino acid, p-benzoyl-L-phenylalanine
}

\section{INTRODUCTION}

Chiral amines are valuable and versatile building blocks for the pharmaceutical, agricultural, and fine chemical industries (Mathew and Yun, 2012; Kelly et al., 2018; Patil et al., 2018). Due to the increasing environmental awareness, the development of new biocatalysts to produce optically pure amines is of primary interest (Fuchs et al., 2015; Slabu et al., 2017). Transaminases (TAs), a class of pyridoxal 5'-phosphate (PLP)-dependent enzymes represent an important biocatalysts that provides a green and cost-effective alternative to transition metal catalysts (Guo and Berglund, 2017). Transaminases (TAs) can be classified into two groups: $\alpha$-transaminases ( $\alpha$-TAs) and $\omega$ transaminases $(\omega$-TAs) depending on the type of substrate that is converted (Steffen-Munsberg et al., 2015). $\alpha$-TAs requires the presence of a carboxyl group at the $\alpha$-position with respect to the carbonyl functionality (Rocha et al., 2019). On the other hand, $\omega$-TAs can accept aliphatic ketones and amines as substrates (that is, not only $\alpha$-keto acids and amino acids). $\omega$-TAs can be further divided into two subgroups, $\beta$-TAs, and amine transaminases (ATAs), the latter being commonly used as a synonym for all $\omega$-TAs (Rocha et al., 2019). High enantiospecificity, broad substrate scope, 
and no need for external cofactor are the beneficial properties of TAs in an industrial context (Steffen-Munsberg et al., 2015). Being PLP-dependent enzymes, TAs can also be classified as $(S)$ selective ATAs belonging to fold-type I (aspartate transaminase superfamily) and $(R)$-selective ATAs belonging to fold-type IV (D-amino acid aminotransferase superfamily) (Slabu et al., 2017). The $(S)$-selective ATAs have been known and widely investigated for industrial use due to their abundance in nature (Lyskowski et al., 2014). In contrast, (R)-ATAs have recently been discovered and are less studied than their $(S)$-selective counterparts (Telzerow et al., 2019). The past decade has seen a surge in the interest in $(R)$-ATAs after successfully utilizing engineered (R)-ATA-117-Rd11 from Arthrobacter sp. KNK168 for the asymmetric synthesis of the antidiabetic drug $(R)$-sitagliptin (Iwasaki et al., 2006; Savile et al., 2010). (R)-ATAs catalyze the transfer of an amino group from $(R)$-aromatic or $(R)$-primary aliphatic amines to pyruvate producing ketones or aldehydes and D-Ala (Schätzle et al., 2011; Iwasaki et al., 2012; Sayer et al., 2014; Iglesias et al., 2017; Lakó et al., 2020). Thermodynamically, deamination of amines is preferable; nonetheless, amination of ketones is possible if a sufficient strategy to shift the equilibrium to amine synthesis is utilized (Schätzle et al., 2011; Iglesias et al., 2017; Telzerow et al., 2019, 2021). Several research groups contributed to this field by identification and characterization of new members and employing protein engineering tools to expand the substrate scope and enhance the thermostability (Iwasaki et al., 2006, 2012; Łyskowski et al., 2014; Guan et al., 2015; Hou et al., 2016; Pavkov-Keller et al., 2016; Bezsudnova et al., 2019; Zeifman et al., 2019; Cheng et al., 2020a; Telzerow et al., 2021). For instance, (R)-ATA from Exophiala xenobiotica has been identified to synthesize biaryl amines, which are considered privileged scaffolds for pharmaceuticals (Telzerow et al., 2019). In parallel, Bornscheuer and colleagues showed the one-pot synthesis of biaryl amine by combining enzymatic and chemical reaction utilizing engineered $(R)$-ATA from Aspergillus fumigatus (Dawood et al., 2018). Moreover, by employing an evolutionary approach, substrate scope and thermostability of $(R)$-ATAs from Mycobacterium vanbaalenii and Aspergillus terreus were enhanced, respectively (Cheng et al., 2020b; Liu et al., 2021). Also, a rationally designed variant V37A of newly characterized (R)-ATA from Luminiphilus syltensis showed broader substrate scope towards bulkier substrates (Konia et al., 2021). Therefore, it is of interest to identify, characterize and engineer more $(R)$-ATAs to provide broad diversity of applications in the chiral amine synthesis.

$(R)$-ATAs are not the only fold type IV PLP dependent enzymes. (Telzerow et al., 2021). D-amino acid aminotransferases (DATAs), L-branched chain aminotransferases (BCATs), and 4-Amino-4deoxychorismate lyases (ADCLs) hold an overall structural similarity, therefore, belong to the same family (Telzerow et al., 2021). Still, their amino acid sequence, activity, stereo preference, and substate scope considerably differ (Bezsudnova et al., 2020). ADCLs catalyze the production of $p$-aminobenzoate from 4 -amino4-deoxychorismate as part of folate biosynthesis (Dai et al., 2013). On the other hand, the specificity of DATAs, BCATs is concerned mainly about $\alpha$-amino and $\alpha$-keto acids while $(R)$-ATAs concerns $(R)$-primary amines (Bezsudnova et al., 2020). Unlike (S)-ATAs, class IV TAs are inert against polyamines and $\beta-, \gamma^{-}$, and $\omega$-amino acids (Bezsudnova et al., 2020). Besides their function, these different subfamilies can also be distinguished by the sequence-based motifs assigned by Bornscheuer and co- workers (Höhne et al., 2010). These motifs have advanced the identification and characterization of several new class IV TAs, thereby providing valuable insights about this fold type (Kelly et al., 2020). Among them (R)-ATAs are of particular interest due to their ability to synthesize enantiomerically pure $(R)$-amines from respective ketones (Ferrandi and Monti, 2018). Thus, it is essential to extend the knowledge of this important enzyme class by identifying and characterizing new members and structure-guided rational design approaches, thereby supporting protein engineering efforts to expand the toolbox of these industrially valuable enzymes (Bezsudnova et al., 2020)., To this end, Voss et al. demonstrated an evolutionary approach for the $(R)$-ATA from DATA using bioinformatic analysis combined with a computational redesign. A sextuple variant (Y31F/H86F/Y88F/H100L/S180A/T242I) was obtained with a specific activity of $326 \mathrm{mU} \mathrm{mg}^{-1}$ in the conversion of (R)-phenylethylamine (1a) (Voss et al., 2020). This study paves an alternate route to expand the toolbox and deepens our understanding of the class IV transaminases.

Although, protein engineering techniques such as rational design and directed evolution have found widespread applications in improving or altering the intrinsic activities of numerous enzymes (Arnold, 2018; Chen and Arnold, 2020). These strategies are primarily based on nature's alphabet of twenty canonical amino acids (cAAs) (Qu et al., 2020; Wang et al., 2021). However, less than half of cAAs have side chains with functional groups involved in enzymes' catalytic mechanisms (Green et al., 2016; Yu et al., 2021). Because of the limited chemical and physical repertoire of cAAs, not surprisingly, enzymes recruit reactive cofactors and post-transnationally modify existing amino acids in the active site (Yu et al., 2018). The advancements in the genetic code expansion (GCE) allow enhanced protein properties by introducing unique functional groups beyond nature's limited building blocks (Wang and Schultz, 2004; Young and Schultz, 2018). To this end, a series of orthogonal amino-acyl transfer RNA (tRNA) synthetase (aaRS)/tRNA pairs have been developed to encode distinct non-canonical amino acids (ncAAs) in vivo (Chin, 2014, 2017; Young and Schultz, 2018; Tseng et al., 2020; Koch et al., 2021; Lee et al., 2021). Over the last 2 decades, more than 200 ncAAs have been genetically encoded in prokaryotes and eukaryotes (Pagar et al., 2021). Apart from peptide modification, antibody development for pharmaceutical use, ncAAs has been widely applied in enzyme engineering research to illustrate the enzyme mechanisms, enhance enzyme activity, and even generate new catalytic mechanisms into protein scaffolds (Agostini et al., 2017; Won et al., 2019b; Drienovská and Roelfes, 2020; Giri et al., 2021; Pagar et al., 2021). The examples include ncAAs with metal chelating, photo-crosslinking, extended disulfide forming, orthogonal reactive, and unique pi-pi interaction properties (Pagar et al., 2021). Although progress in this field is fast, only a handful of examples have been reported for remodelling enzyme active sites by introducing single ncAA resulting in improved activity and substrate scope compared to cAAs 
(Pagar et al., 2021). The major bottlenecks for the practical utilization of ncAAs in enzyme engineering are lower expression yields, high cost or unavailability of the ncAAs, background incorporation of cAAs, and limited structural diversity of ncAAs utilizing only orthogonal tyrosyl/pyrrolysyltRNA synthetases (Agostini et al., 2017; Drienovská and Roelfes, 2020). Nonetheless, continued efforts to overcome the above limitations open new doors in enzyme engineering and serve as a toolkit for evolution and designing enzymes with desired functionality (Pagar et al., 2021). In this work, we report ncAAbased engineering of $(R)$-ATA previously created from DATA scaffold. The rational incorporation of ncAA has significantly improved enzyme functionality. These results uncover the great potential of engineering enzymes with ncAAs for the efficient synthesis of chiral amines.

\section{MATERIALS AND METHODS}

\section{Materials}

The plasmids pDule-tfmF A65V S158A (ID: 85484) (MiyakeStoner et al., 2010) and PylRS-AS (ID:137908) (Lee et al., 2016) were purchased from Addgene (Watertown, MA, United States). The gene for $(R)$-ATA and primers were synthesised and sequenced by BIONICS Co., Ltd. (Seoul, South Korea). The 2,3,4-triflourophenylalanine (F3F) was purchased from ChemImpex Inc (Wood Dale, IL, United States), $p \mathrm{BpA}$ and $p$ methylphenylalanine $(p \mathrm{MeF})$ were purchased from BACHEM (Bubendorf, Switzerland), and $p$-trifluoromethylphenylalanine ( $p$ tFMF) from Alfa Aesar. Ni-NTA affinity columns were purchased from Qiagen (Valencia, CA, United States). All the other chemicals like pyruvate, acetophenone, pyridoxal $5^{\prime}$ phosphate and amino donors were purchased from SigmaAldrich, Korea.

\section{Site Directed Mutagenesis}

The plasmid pET24ma harboring a gene for (R)-ATA was utilized as a template for inserting TAG codon as well as Ala mutations. The list of primers used is given in Supplementary Table S1. The thermal cycler was programmed as 1) initial denaturation at $95^{\circ} \mathrm{C}$ for $2 \mathrm{~min}, 2) 18$ cycles of denaturation at $95^{\circ} \mathrm{C}$ for $30 \mathrm{~s}$, annealing at $58^{\circ} \mathrm{C}$ for $30 \mathrm{~s}$ (depending on the $T_{\mathrm{m}}$ of the primers) and extension at $72^{\circ} \mathrm{C}$ for $5 \mathrm{~min}$; 3) a final extension at $72^{\circ} \mathrm{C}$ for 5 min (Sarak et al., 2021). The resulting PCR product was digested with $\mathrm{DpnI}$ for $2 \mathrm{~h}$ at $37^{\circ} \mathrm{C}$ and transformed into chemically competent E. coli DH5-alpha cells. A single colony was picked from LB plates supplemented with Kanamycin and cultured overnight in $5 \mathrm{ml}$ of LB media. The plasmids were isolated, and the gene was sequenced to confirm desired mutation.

\section{ncAA Incorporation and Purification of the Mutant Enzymes}

The plasmid pET24ma harboring the gene encoding for $(R)$-ATA and the TAG codon variants were individually co-transformed with PylRS-AS or pDule-tfmF A65V S158A or pEVOL- $p$ BpARS (Park et al., 2018) into chemically competent E. coli. (BL-21) cells.
A single colony of host cells was incubated overnight into $5 \mathrm{ml}$ LB-media supplemented with respective antibiotics. The selected ncAAs were incorporated into target enzyme by the reported protocols for each ncAAs (Chin et al., 2002; Jackson et al., 2007; Miyake-Stoner et al., 2010; Lee et al., 2016). The expression of pBpARS and $\mathrm{F}_{3}$ FPylRS was induced by $0.2 \%$ arabinose and expression of target enzyme was induced by $0.1 \mathrm{mM}$ IPTG. The overexpressed cells were harvested by centrifugation at $5,000 \mathrm{rpm}, 4^{\circ} \mathrm{C}$ for $10 \mathrm{~min}$. The pellet was suspended in an appropriate volume of the lysis buffer $\left(\mathrm{NaH}_{2} \mathrm{PO}_{4}(50 \mathrm{mM})\right.$, $\mathrm{NaCl}$ (300 mM), imidazole (5 mM, pH 8.0)). The cell suspension was then subjected to ultrasonic disruption by a horn-type sonicator (Sonics\& Material Inc, United States). During sonication, the sample tube containing the cell mass suspension was held in an ice bath. The sonication was carried for the total duration of $30 \mathrm{~min}$, with a duty cycle of $37.5 \%$. The cell lysate was centrifuged at $17,000 \mathrm{rpm}$ for $30 \mathrm{~min}$ and supernatant was loaded on Ni-NTA agarose resin column [BabyBio] with the flow rate of $1 \mathrm{ml} / \mathrm{min}$. The non-target proteins were washed with $100 \mathrm{ml}$ of washing buffer $(50 \mathrm{mM}$ $\mathrm{NaH}_{2} \mathrm{PO}_{4}, 300 \mathrm{mM} \mathrm{NaCl}$ and $20 \mathrm{mM}$ imidazole, $\mathrm{pH}$ 8.0) with flow rate of $2 \mathrm{ml} / \mathrm{min}$. Next, the desired protein containing C-terminal hexa-His-tag was eluted using elution buffer 1 $\left(50 \mathrm{mM} \mathrm{NaH} \mathrm{PO}_{4}, 300 \mathrm{mM} \mathrm{NaCl}\right.$ and $250 \mathrm{mM}$ imidazole, $\mathrm{pH}$ 8.0). The eluted solution containing the purified protein was dialyzed against $20 \mathrm{mM}$ Tris- $\mathrm{HCl}$ buffer ( $\mathrm{pH}$ 8.0) and concentrated using an Amicon $30 \mathrm{~K}$ ultrafiltration unit.

\section{Determination of Enzyme Activity}

All enzyme assays were carried out at $37^{\circ} \mathrm{C}$ and $100 \mathrm{mM}$ Tris- $\mathrm{HCl}$ buffer (pH-9.0). Standard substrate conditions for activity assay were $10 \mathrm{mM}(R)-1 \mathrm{a}, 10 \mathrm{mM}$ pyruvate and $0.1 \mathrm{mM}$ PLP. The typical reaction volume was $500 \mu \mathrm{L}$, and the enzyme reaction was stopped after $30 \mathrm{~min}$ by adding $500 \mu \mathrm{L} 10 \%$ perchloric acid. Acetophenone produced was analysed by HPLC. Here, different concentrations of enzymes were used to measure the exact specific activity.

\section{Determination of Substrate Specificity}

Amino acceptor specificity was measured by using $10 \mathrm{mM}(R)-1 \mathrm{a}$ as an amino donor and $10 \mathrm{mM}$ amino acceptor at $37^{\circ} \mathrm{C}$ and $100 \mathrm{mM}$ Tris Hcl buffer ( $\mathrm{pH}-9.0)$ for $30 \mathrm{~min}$. Acetophenone produced was analysed by HPLC. Amine substrate specificity was measured using $10 \mathrm{mM}$ pyruvate and $10 \mathrm{mM}$ respective amine compound (1a-1e) solubilized using 10\% DMSO. Respective ketone product formed in each reaction after $30 \mathrm{~min}$ was analyzed by HPLC.

\section{Analytical Conditions}

Acetophenone and other ketone products were analyzed using a $\mathrm{C}_{18}$ Symmetry column (Agilent) with an elution mixture of $50 \%$ methanol ( $0.1 \%$ TFA) and $50 \%$ water $(0.1 \%$ TFA $)$ at a flow rate of $1.0 \mathrm{ml} / \mathrm{min}$ at $244 \mathrm{~nm}$ detection wavelength. The quantitative analysis of amines was measured using HPLC with a Crownpak CR (Daicel Co., Japan) column at $210 \mathrm{~nm}$ with an elution of $\mathrm{pH} 1.5$ perchloric acid solution $\left(0.6 \mathrm{ml} \mathrm{min}^{-1}\right)$. 

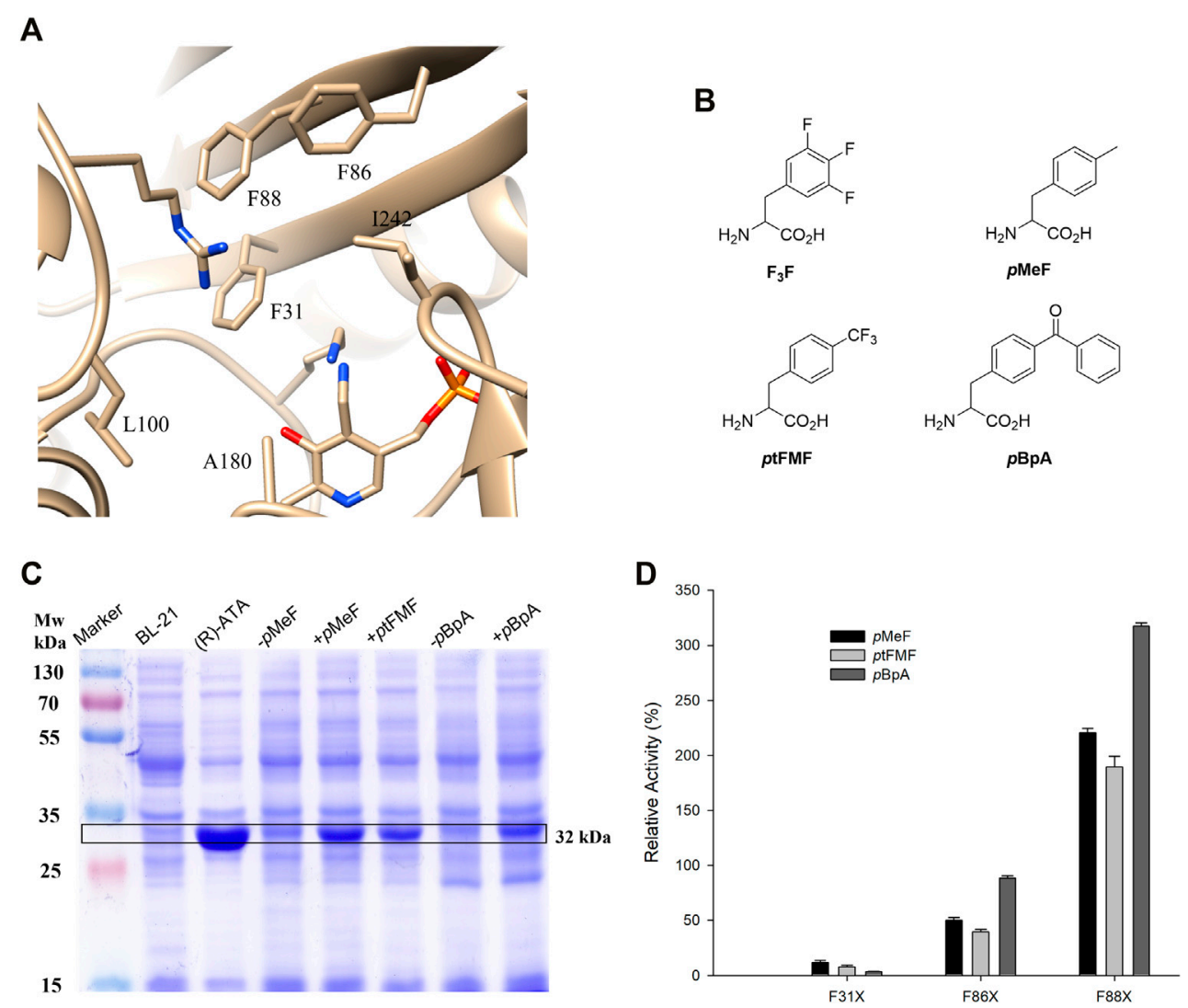

FIGURE 1 | (A) Active site residues of rationally designed (R)-ATA from DATA scaffold. (B) Structures of ncAAs selected for incorporation into active site of (R)-ATA (C) Coomassie-stained SDS-PAGE showing expression of proteins in presence and absence of ncAAs; (D) Relative activities of variants containing three selected ncAAs at $31^{\text {st }}, 86^{\text {th }}$ and $88^{\text {th }}$ position. The specific activity of parent $(R)$-ATA (324 mU mg ${ }^{-1}$ ) was taken as $100 \%$.

\section{RESULTS AND DISCUSSION}

\section{Incorporation of ncAAs Into (R)-ATA}

Class IV TAs are promising catalysts for synthesizing enantiomerically pure amines and D-amino acids (Bezsudnova et al., 2020). The development of (R)-ATA for manufacturing sitagliptin demonstrated the practical viability of $(R)$-ATAs for asymmetric synthesis on an industrial scale (Savile et al., 2010). It sparked new research in the field of $(R)$ ATAs in synthetic applications. Yet, narrow ketone substrate range, unfavourable reaction equilibria, and strong ketone inhibition limit the applicability of these enzymes (SteffenMunsberg et al., 2015; Guo and Berglund, 2017). In conjunction with identifying new TAs, structure-guided rational design approaches could help overcome these bottlenecks (Steffen-Munsberg et al., 2015). To this end, Voss et al. studied two members from fold type IV, BCAT and DATA, and their respective variants to accept the benchmark amine substrate 1a. By employing bioinformatic analysis combined with the computational redesign, a DATA variant (M2-6) harbouring six mutations (Y31F/H86F/Y88F/ H100L/S180A/T242I) (Figure 1A), was generated yielding a total activity of $326 \mathrm{mU} \mathrm{mg}^{-1}$ toward 1a. A significant increase in active site volume by non-polar side chain mutations contributed to the favourable binding of bulkier and hydrophobic la over D-alanine. Despite bearing moderate (R)-ATA activity, the rational engineering of DATA deepens our knowledge of how substrate specificity in $\alpha$ ATA is affected and can be altered toward accepting arylamines. Notably, three among six mutations introduced were $\mathrm{Y} 31 \mathrm{~F} / \mathrm{H} 86 \mathrm{~F} / \mathrm{Y} 88 \mathrm{~F}$, vastly contributing to the active site's hydrophobicity. The rational design approach based on cAAs limits to create a more hydrophobic environment into the active site as Phe is highly hydrophobic among all cAAs. The GCE strategies allow the incorporation of more than 200 ncAAs with different functional properties into proteins (Won et al., 2019b; Pagar et al., 2021). Therefore, we speculate that substitution of Phe by a ncAA with a more hydrophobic side chain could enhance the activity of this rationally designed enzyme. Initially, we selected four Phe analogs, namely, $\mathrm{F}_{3} \mathrm{~F}, p \mathrm{tFMF}, p$-methylphenylalanine $p \mathrm{MeF}$, and $p \mathrm{BpA}$, based on commercial availability and hydrophobicity of the side chains (Figure 1B). An amber stop codon was substituted for three individual Phe residues (F31, F86, and F88). Initially, the incorporation efficiencies of selected ncAAs were determined by incorporating each ncAA 


\begin{tabular}{|c|c|c|c|}
\hline Mutant & F31 & F86 & F88 \\
\hline 1 & $\mathrm{~F}$ & $\mathrm{~F}$ & $\mathrm{~F}$ \\
\hline 2 & A & $p \mathrm{BpA}$ & $\mathrm{F}$ \\
\hline 3 & A & $\mathrm{F}$ & $p \mathrm{BpA}$ \\
\hline 4 & $\mathrm{~F}$ & A & $p \mathrm{BpA}$ \\
\hline 5 & $F$ & $p \mathrm{BpA}$ & $A$ \\
\hline 6 & A & A & $p \mathrm{BpA}$ \\
\hline
\end{tabular}

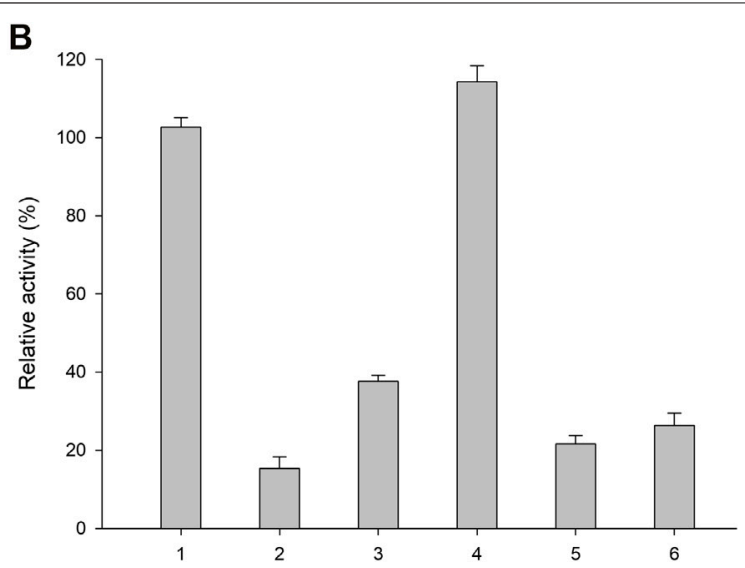

FIGURE 2|Alanine scanning of the active site of $(R)$-ATA (A) Mutations introduced into active site of $(R)$-ATA having one $p B p A$ and another Phe mutated to Ala. (B)

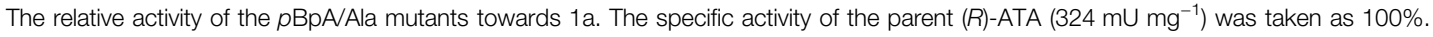

at the $31^{\text {st }}$ position using available orthogonal tRNA synthetase/tRNA pairs evolved for each ncAA (Supplementary Table S2). The incorporation efficiency of $\mathrm{F}_{3} \mathrm{~F}$ using evolved Methanosarcina mazei pyrrolysyl-tRNA synthetase/tRNA pair was comparatively poor (Supplementary Figure S1), and media shift, high concentration of ncAA $(5 \mathrm{mM})$ longer expression time, is quite unpractical for obtaining higher concentrations of the mutant enzyme. The tRNA synthetase/tRNA pair evolved from Methanococcus jannaschii tyrosyl tRNA synthetase for $p \mathrm{MeF}, p \mathrm{tFMF}$ and $p \mathrm{BpA}$ incorporation showed better incorporation efficiency and fidelity (Figure 1C). Therefore, total nine mutants containing each of three ncAAs at $31^{\text {st }}, 86^{\text {th }}$ and $88^{\text {th }}$ position were purified along with their parent $(R)$ ATA and subjected to an activity assay, which was conducted using $10 \mathrm{mM}$ la and $10 \mathrm{mM}$ pyruvate in $100 \mathrm{~mm}$ Tris/ $\mathrm{HCl}$ buffer ( $\mathrm{pH}$ 9.0). One unit was defined as the amount of enzyme that catalysed the formation of $1 \mu \mathrm{mol}$ of acetophenone per minute. Incorporation of ncAAs at $31^{\text {st }}$ position showed deleterious effects on the TA activity, implying F31 is highly conserved. Remarkably, replacing F88 with all three ncAAs displayed higher activities than the parent enzyme with highest 3-fold activity by F88pBpA (Figure 1C). This enhanced activity was in close agreement with the previous finding where replacement of the Y88 with Phe showed a beneficial effect on (R)-PEA acceptance (Voss et al., 2020). On the other hand, replacing F86 with $p \mathrm{MeF}$ and $p$ tFMF showed $\sim 50$ and $61 \%$ reduction in activity, respectively, while $\mathrm{pBpA}$ hardly affected the enzyme activity.

\section{Reshaping of the Active Site}

Encouraged by the above results, we further aimed to reshape the active site of $(R)$-ATA with ncAA. Three Phe residues provide enough hydrophobicity to the active site but significantly compromise the substrate-binding pocket's size and thus narrow the substrate scope. Therefore, we envisioned that the hydrophobicity provided by single $p \mathrm{BpA}$ introduced into the active site might compensate for Phe residue's replacement. Ala and Phe have hydrophobic side chains, but the earlier is much smaller and more flexible than the latter. Therefore, an Ala scan was performed on three selected Phe residues while retaining one residue as $p \mathrm{BpA}$. Mutant combinations with $\mathrm{F} 31 p \mathrm{BpA}$ were omitted owing to the detrimental effect of $p \mathrm{BpA}$ substitution at 31 st position (Figure 1C). Total five mutants were designed (Figure 2A), and activities of the resulting variants were measured against 1a. Significant reductions in enzyme activity toward la were observed, apparently due to the impairment of the hydrophobic environment required to recognize the phenyl group of 1a (Figure 2B). In contrast, variant F86A/F88pBpA showed activity comparable to the parent enzyme, suggesting F31 and F88 residues play an essential role in recognizing the phenyl ring of 1a. Additionally, the loss of hydrophobicity by replacing F86 with Ala was compensated by $p \mathrm{BpA}$, thereby retaining the

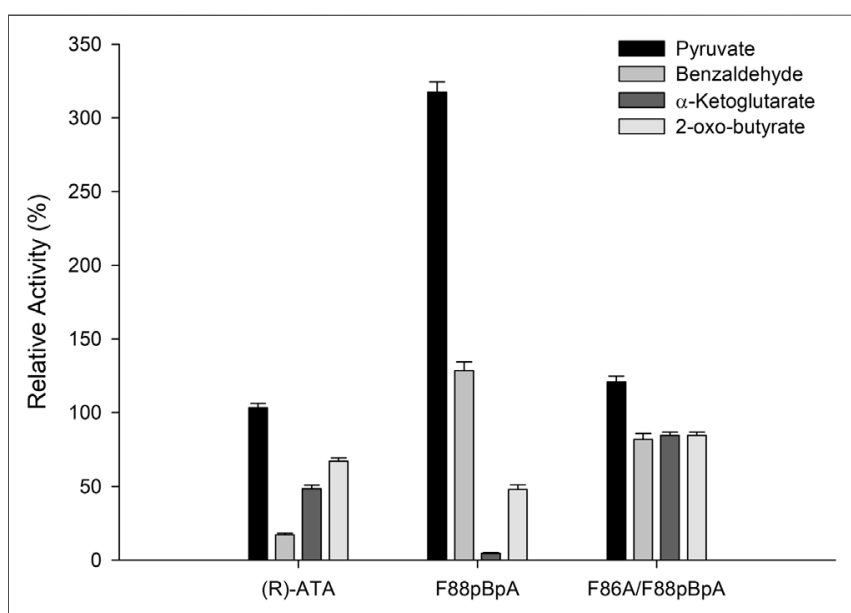

FIGURE 3 | Substrate specificities of the (R)-ATA and its variants towards various amino acceptors. (R)-ATA activity towards pyruvate (324 mU $\mathrm{mg}^{-1}$ ) was taken as $100 \%$. 
A<smiles>CC(N)c1ccccc1</smiles><smiles>CC(N)c1ccc(F)cc1</smiles><smiles>Cc1ccc(C(C)N)cc1</smiles><smiles>CC(N)c1ccc(O)cc1</smiles>

1d<smiles>CCC(N)c1ccccc1</smiles>

$1 \mathrm{~g}$
$1 \mathrm{~b}$

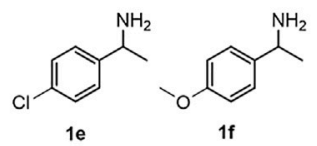<smiles>CCCC(N)c1ccccc1</smiles>

$1 \mathrm{~h}$

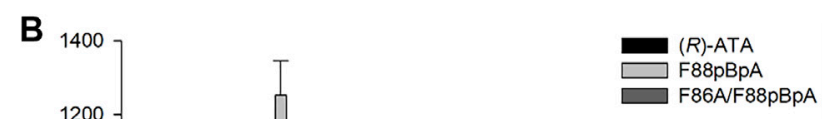

FIGURE 4 | Amino donor specificity of selected (R)-ATA mutants (A) Substrate structures and (B) Relative activity. Different concentrations of the enzyme were used to determine specific activity exactly. Specific activity of $(R)$-ATA for 1a (324 mU $\mathrm{mg}^{-1}$ ) was taken as $100 \%$.

overall enzyme activity. The variant F86A/F88pBpA was taken for further characterization.

\section{Substrate Specificity of the Designed Variants}

Next, the substrate specificities of parent (R)-ATA, F88pBpA, and $\mathrm{F} 86 \mathrm{~A} / \mathrm{F} 88 \mathrm{pBpA}$ were investigated using a series of commonly used amino acceptors like pyruvate, benzaldehyde, $\alpha$ ketoglutarate, and 2-oxobutyrate, using $1 \mathrm{la}$ as an amino donor. Pyruvate served as the best amino acceptor for all the variants, and F88pBpA showed a specific activity of $1.03 \mathrm{U} \mathrm{mg}^{-1}$. Interestingly, F88pBpA and F86A/F88pBpA showed $\sim 8$ - and 5 -fold higher activities respectively, for benzaldehyde than the parent enzyme (Figure 3). This increased activity could be attributed to the enhanced acceptance of aromatic substrates by $p \mathrm{BpA}$ incorporation. As a cheaper amino acceptor than pyruvate, benzaldehyde can be suitable for TA reactions. In contrast, the activity of $\mathrm{F} 88 \mathrm{pBpA}$ variant towards $\alpha$ ketoglutarate has been drastically reduced while F86A/ F88 $p$ BpA retained its activity towards all amino acceptors.

Moreover, the substrate specificities of variants were examined for various substituted arylamines (1a-h) as shown in Figure 4A using pyruvate as an amino acceptor. The respective ketone product formed in $10 \mathrm{mM}$ reaction was quantified by HPLC. While parent enzyme showed mediocre activities towards 1a-d and $1 \mathrm{~g}, \mathrm{~F} 88 \mathrm{pBpA}$ and $\mathrm{F} 86 \mathrm{~A} / \mathrm{F} 88 \mathrm{pBpA}$ showed significantly enhanced activities (Figure 4B). Notably, 1g carrying a $26 \%$ parental reactivity relative to 1 a showed the highest $\sim 15$-fold enhancement in activity upon F88pBpA substitution. Notably, parent $(R)$-ATA and its variants were able to accept ethyl side chain into P-pocket (small-binding pocket) which is uncommon among most of the naturally occurring (R)-ATAs (Cheng et al., 2020b; Konia et al., 2021). In addition, $\sim 12$-fold enhanced activity for 1d which is carrying $p$-hydroxy substitution, suggests that even a polar substituted aryl amine's acceptance has been improved by $\mathrm{F} 88 \mathrm{pBpA}$ substitution. Unfortunately, none of the mutant showed activity for $1 \mathrm{e}$, If and $1 \mathrm{~h}$. F86A/F88pBpA was expected to have a broader substrate scope due to enlarged active site by F86A mutation. Nevertheless, more active site remodelling efforts are still necessary to improve the substrate scope of this rationally designed enzyme.

\section{Effect of pBpA Incorporation on Stability}

It has been observed that improved activity or substrate specificity of enzymes leads to a trade-off between stability in many instances (Siddiqui, 2017; Yu and Dalby, 2018). However, it is worth mentioning that the (R)-ATA utilized herein was previously created from the DATA from Bacillus subtilis without affecting overall stability (Voss et al., 2020). Incorporation of halogenated ncAAs by selective pressure incorporation or site-specific incorporation in several instances has enhanced the stability of enzymes (Hoesl et al., 2011; Deepankumar et al., 2014; Carlsson et al., 2018; Ohtake et al., 2018; Won et al., 2019a). Nevertheless, incorporation of single $p \mathrm{BpA}$ has not yet been reported for improved stability. Therefore, we were curious whether incorporating $p \mathrm{BpA}$ into $(R)$-ATA affected the stability. To this end, we examined the residual activity of the variants by incubating enzyme samples at various temperatures $\left(37-60^{\circ} \mathrm{C}\right)$ in the presence of $100 \mathrm{mM}$ Tris $\mathrm{HCl}(\mathrm{pH}-9.0)$ for $30 \mathrm{~min}$ (Figure 5A). Unfortunately, the most active variant $\mathrm{F} 88 \mathrm{pBpA}$ and the parent enzyme lost almost $45 \%$ of their intrinsic activity after incubating at $55^{\circ} \mathrm{C}$, while $\mathrm{F} 86 \mathrm{~A} / \mathrm{F} 88 \mathrm{pBpA}$ retained $85 \%$ of its original activity. These results demonstrate that enhanced activity does not necessarily lead to a trade-off with stability as best variant F88pBpA showed a similar stability profile with the parent enzyme. On the other hand, F86A/F88pBpA showed greater thermostability than the parent enzyme, indicating that it is indeed possible to tune the activity and stability profiles of the enzymes using ncAAs. Moreover, the thermal stability of enzyme variants was examined under different conditions because 1a diminishes stability due to 
A

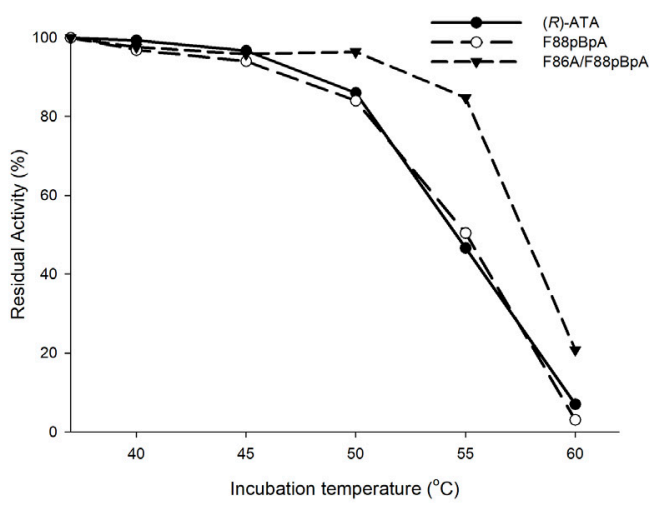

C

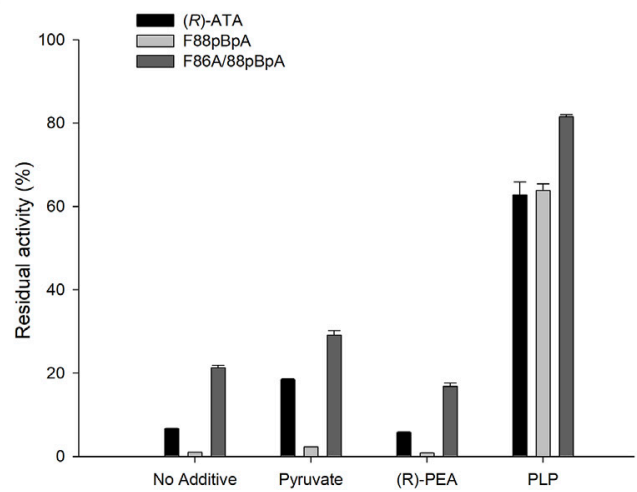

B

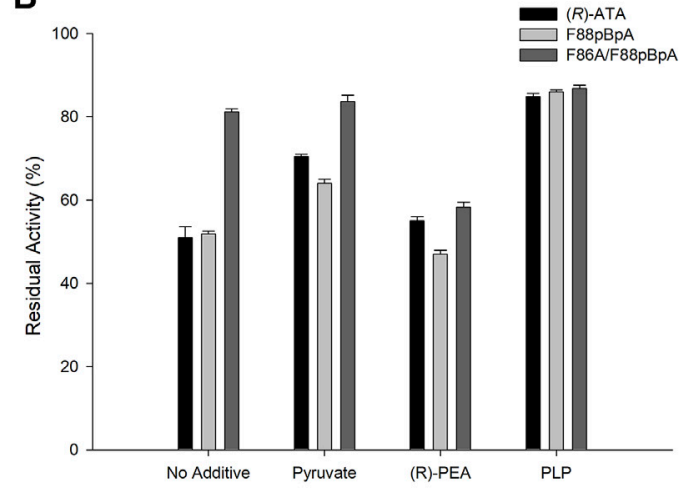

D

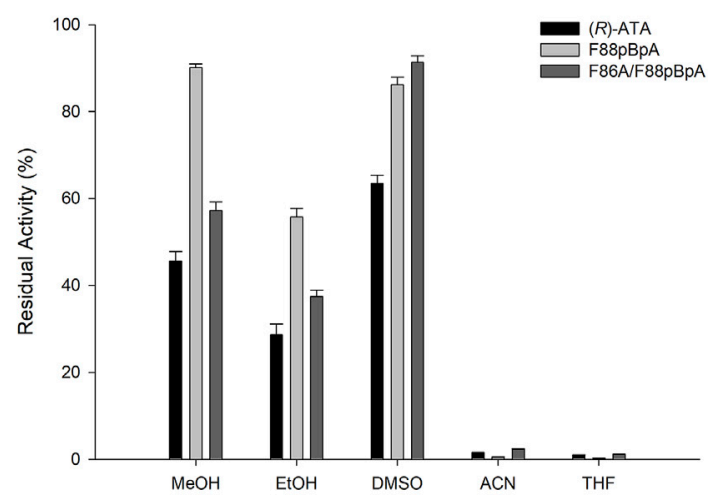

FIGURE 5 | (A) The residual activity of $(R)$-ATA and its variants at $37-60^{\circ} \mathrm{C}$ without any additive. The residual activity of $(R)$-ATA and its variants in the presence of pyruvate, 1a, and PLP at (B) $55^{\circ} \mathrm{C}$, and (C) $60^{\circ} \mathrm{C}$. (D) The residual activity of $(R)$-ATA and its variants in the presence of different organic solvents $(20 \%$ v $/ \mathrm{V})$.

formation of E-PMP (Deepankumar et al., 2014; Mathew et al., 2016). In contrast, pyruvate and PLP have a beneficial effect on stability. The residual activities of enzymes were further examined after $30 \mathrm{~min}$ of incubation in $100 \mathrm{mM}$ Tris/ $\mathrm{HCl}$ buffer $(\mathrm{pH}-9.0)$ at 55 and $60^{\circ} \mathrm{C}$ and in the presence of $10 \mathrm{Mm} \mathrm{1a}, 10 \mathrm{mM}$ pyruvate, or $0.1 \mathrm{mM}$ PLP. Interestingly parent $(R)$-ATA and F88pBpA regain their stability at $55^{\circ} \mathrm{C}$ in presence of PLP displaying $83 \%$ overall activity similar to F86A/F88pBpA (Figure 5B). Next, the enzyme activities were significantly decreased at $60^{\circ} \mathrm{C}$ in presence of $1 \mathrm{a}$ and without additive, whereas PLP showed stabilizing effect by forming E-PLP complex. Variant F86A/F88pBpA retained highest $81 \%$ of activity where native enzyme and $\mathrm{F} 88 \mathrm{pBpA}$ lost $\sim 35 \%$ of their original activity at $60^{\circ} \mathrm{C}$ (Figure 5C). Owing to the poor solubility of keto or amine substrates in aqueous buffer solutions, organic solvents are generally used as a cosolvent. Therefore, the stability of enzyme variants was also examined in presence of various organic solvents $(20 \% \mathrm{v} / \mathrm{v})$ like methanol, ethanol, DMSO, acetonitrile and tetrahydrofuran. All the variants showed better stability after incubation in presence of DMSO and methanol whereas, complete loss of activity was observed in presence of acetonitrile and tetrahydrofuran (Figure 5D). In agreement with enhanced stability, F86A/F88pBpA also showed better organic solvent tolerance in presence of $20 \%$ DMSO than other variants.

\section{Kinetic Resolution of Amines}

Incorporation of ncAAs into enzymes enables a dramatic expansion of their catalytic features. However, the biocatalytic use of enzymes containing ncAAs lacks behind the use of ncAAs as tools for therapy and research (Pagar et al., 2021). Low expression levels, high cost or unavailability of ncAAs, unfolded enzymes, incompletely translated enzymes and background incorporation of the cAAs are the major bottlenecks for the GCE method from being a standard method for enzyme engineering (Drienovská et al., 2020). Expression yield of the protein containing ncAA also reflects the degree by which mutation is tolerated (Kolev et al., 2014). For instance, the expression yields of F88pBpA and F86A/F88pBpA were $32-35$ and $68-70 \mathrm{mg} / \mathrm{L}$ respectively whereas parent $(R)$ ATA co-expressed with $p$ BpARS yielded $\sim 134-140 \mathrm{mg} / \mathrm{L}$ of protein. Also, affinity purification is rather unpractical for screening of large set of mutants or large scale biocatalytic process. Therefore, we performed the kinetic resolution of racemic amines using whole cell despite the fact that expression levels of soluble enzymes harboring $p \mathrm{BpA}$ will be less than parent $(R)$-ATA (Figure 1C). Since, pyruvate was a good amino acceptor for all variants, the kinetic resolution of $20 \mathrm{mM}$ $1 \mathrm{a}-1 \mathrm{~d}$ and $1 \mathrm{~g}$ was carried out with equimolar concentration of pyruvate (Supplementary Figure S2-6). As shown in Table 1 after $24 \mathrm{~h}$ reaction, $50 \%$ conversion of $1 \mathrm{~g}$ with $>99 \%$ ee was 
TABLE 1 | Kinetic resolution of various amine compounds using parent $(R)$-ATA and its variants.

\begin{tabular}{|c|c|c|c|c|c|c|}
\hline \multirow[t]{2}{*}{ Substrate } & \multicolumn{2}{|c|}{ Parent $(R)$-ATA } & \multicolumn{2}{|c|}{ F88pBpA } & \multicolumn{2}{|c|}{ F86A/F88pBpA } \\
\hline & Conversion (\%) & ee $(\%)$ & Conversion (\%) & ee $(\%)$ & Conversion (\%) & ee $(\%)$ \\
\hline $1 a$ & 22 & 28 & 17 & 21 & 27 & 38 \\
\hline $1 b$ & 50 & $>99$ & 44 & 78 & 50 & $>99$ \\
\hline $1 c$ & 38 & 60 & 36 & 57 & 43 & 76 \\
\hline $1 d$ & 34 & 52 & 41 & 70 & 40 & 68 \\
\hline $1 \mathrm{~g}$ & 36 & 56 & 45 & 83 & 50 & $>99$ \\
\hline $1 \mathrm{~g}^{*}$ & 50 & $>99$ & 50 & $>99$ & 50 & $>99$ \\
\hline
\end{tabular}

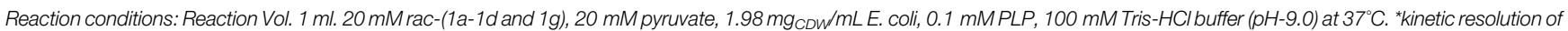
$10 \mathrm{mM}$ rac-1g using $20 \mathrm{mM}$ benzaldehyde as an amino acceptor instead of pyruvate.

achieved by F86A88pBpA whereas, F88pBpA and parent $(R)$ ATA showed only 45 and $36 \%$ conversion, respectively. Mutant F86A/F88pBpA performed well than F88pBpA for all the substrates perhaps due to its higher stability and expression levels. For the kinetic resolution of amines, it is necessary to add stoichiometric quantities of pyruvate which is used as an amino acceptor. However, pyruvate itself is an expensive compound and thus increases the overall cost of the biocatalytic production of amines (Shin et al., 2015). Interestingly, $\mathrm{F} 88 \mathrm{pBpA}$ showed considerable reactivity towards benzaldehyde (Figure 3) as $463 \mathrm{mU} \mathrm{mg}^{-1}$ suggesting that very cheap benzaldehyde can be used as a good amino acceptor. Therefore, kinetic resolution of $10 \mathrm{mM} 1 \mathrm{~g}$ was performed using $20 \mathrm{mM}$ benzaldehyde. Highly enantiomerically pure $(S)$ $1 \mathrm{~g}$ with $50 \%$ conversion and $>99 \%$ ee was obtained by parent $(R)$ ATA and its variants (Supplementary Figure S7). This result clearly demonstrates the applicability of mutant TAs using benzaldehyde as a cheap amino acceptor in a kinetic resolution reaction system for producing optically pure amines.

The kinetic resolution is not an efficient way to utilize $(R)$-ATAs for synthesizing $(S)$-amines. Several $(S)$-selective ATAs can be employed to produce $(S)$-enantiomers with a theoretical yield up to $100 \%$ by asymmetric synthesis (Mathew and Yun, 2012; Slabu et al., 2017; Kelly et al., 2018; Patil et al., 2018). Therefore, we tried to perform $(R)$-ATA catalyzed asymmetric synthesis of $(R)-1 \mathrm{~g}$ from propiophenone using benzylamine as an amino donor. Though enzymes utilized in this study were reactive for deamination of $(R)-1 g$, they could not perform the reverse reaction, i.e., amination of the propiophenone. This indicates that, unlike most of the $\omega$-TAs, enzyme variants utilized herein do not follow the "good donor-acceptor pair relationship" (Han et al., 2017). However, we believe that F88pBpA or F86A/F88pBpA may serve as a good template for protein engineering to obtain efficient biocatalysts to produce bulky $(R)$-amines.

\section{DISCUSSION}

ATAs are the PLP dependent enzymes which catalyze the transfer of an amino group from an amino donor to a carbonyl moiety and vice versa (Steffen-Munsberg et al., 2015). Transaminase reactions gain popularity for the production of chiral amines because of their outstanding optical purity, high yield, broad substrate specificity, and environmental friendliness (Patil et al., 2018). On account of their importance in asymmetric biocatalysis, the identification and characterization of new members and engineering efforts to improve their functional properties are of utmost importance (Steffen-Munsberg et al., 2015).

Transaminase classification has recently been revised (Gao et al., 2017). To date, only a few (R)-ATA are identified, and their crystal structures were made available, allowing researchers to get insight into the enantioselectivity and explore the catalytic mechanism compared to their $(S)$-selective counterparts (Konia et al., 2021). Furthermore, researchers used molecular modeling and the structure-activity relationship to create the enzymes (Voss et al., 2020). However, problems like an unfavorable equilibrium constant and the inability to accept bulky substrates still need to be addressed (Bezsudnova et al., 2020). Although engineering ( $R$ )-ATA from Arthrobacter sp. was a noteworthy, the rational quest for more relevant $(R)$-ATAs is still ongoing because it will lay the groundwork for these enzymes' future applications (Savile et al., 2010).

The chemical modification and ncAA incorporation methods have emerged as an important alternative to the traditional enzyme engineering approaches like directed evolution and rational design (Giri et al., 2021; Pagar et al., 2021). These methods used independently or together have dramatically expanded the chemical diversity for proteins, which has provided protein engineers with powerful tools for enzymes engineering (Pagar et al., 2021). Over the past few decades, numerous studies have reported increased enzyme activity and stability by incorporating the ncAAs (Agostini et al., 2017; Drienovská and Roelfes, 2020). In a pioneering example, Jackson and others demonstrated that sitespecific incorporation of ncAAs can be used to redesign the enzyme's active site for diverse substrates, resulting in a $~ 30$ fold increased activity that cannot be reproduced by substituting any other cAA (Jackson et al., 2006).

In this study, we demonstrated the ncAA-based engineering approach to enhance the functionality of rationally designed $(R)$ ATA. Based on the preliminary knowledge that hydrophobicity is a major contributing factor for the creation of $(R)$-ATA activity, we explored it further using ncAA incorporation. The designed variant containing $\mathrm{pBpA}$ at $88^{\text {th }}$ position has significantly enhanced the activity towards several arylamine substrates. Moreover, another engineered variant F86A/F88pBpA showed enhanced thermostability and organic solvent tolerance. These results clearly demonstrate that a wise selection of ncAAs for rational engineering of the enzymes can render beneficial results 
for functional enhancement. However, further engineering efforts are still needed to improve the substrate scope of this enzyme. To this goal, simultaneous incorporation of ncAAs using mutually orthogonal aminoacyl tRNA synthetases/tRNA pairs for the incorporation of distinct ncAAs into one protein could be beneficial (Neumann et al., 2010; Italia et al., 2019). Moreover, directed evolution with ncAAs can also be utilized to enlarge the chemical and sequence space of proteins and, in turn, increase the probability of evolving the desired mutant (Pagar et al., 2021; Pan et al., 2021).

The main obstacle in the ncAA-based enzyme engineering and directed evolution approach is exogenous supplementation of often expensive ncAA into the growth medium (Pagar et al., 2021). This increases the overall production cost of the ncAA containing enzymes. Autonomous biosynthesis of ncAAs and their concurrent incorporation into enzyme of interest in vivo could significantly reduce the production cost and permeability issues (Pagar et al., 2021). Using enzymatic and metabolic pathways, some ncAAs like $p$-amino-phenylalanine, 5-hydroxytryptophan, L-phosphothreonine, L-dihydroxyphenylalanine, fluorotyrosine, and $S$-allylcysteine were biosynthesized in E. coli and concurrently incorporated into target proteins (Ma et al., 2014; Exner et al., 2017; Kim et al., 2018; Won et al., 2019a; Nojoumi et al., 2019; Schipp et al., 2020). The production of an increasing number of ncAAs in engineered cells will be aided by advances in biochemistry, molecular biology, and synthetic biology. In addition, advancements in ncAA mutagenesis procedures may drive ncAAs more valuable in protein engineering and enzyme evolution (Pagar et al., 2021).

\section{REFERENCES}

Agostini, F., Völler, J. S., Koksch, B., Acevedo-Rocha, C. G., Kubyshkin, V., and Budisa, N. (2017). Biocatalysis with Unnatural Amino Acids: Enzymology Meets Xenobiology. Angew. Chem. Int. Ed. 56, 9680-9703. doi:10.1002/anie.201610129

Arnold, F. H. (2018). Directed Evolution: Bringing New Chemistry to Life. Angew. Chem. Int. Ed. 57, 4143-4148. doi:10.1002/anie.201708408

Bezsudnova, E. Y., Boyko, K. M., Nikolaeva, A. Y., Zeifman, Y. S., Rakitina, T. V., Suplatov, D. A., et al. (2019). Biochemical and Structural Insights into PLP Fold Type IV Transaminase from Thermobaculum Terrenum. Biochimie 158, 130-138. doi:10. 1016/j.biochi.2018.12.017

Bezsudnova, E. Y., PopovPopov, V. O. A., and Boyko, K. M. (2020). Structural Insight into the Substrate Specificity of PLP Fold Type IV Transaminases. Appl. Microbiol. Biotechnol. 104, 2343-2357. doi:10.1007/s00253-020-10369-6

Carlsson, A.-C. C., Scholfield, M. R., Rowe, R. K., Ford, M. C., Alexander, A. T., Mehl, R. A., et al. (2018). Increasing Enzyme Stability and Activity through Hydrogen BondEnhanced Halogen Bonds. Biochemistry 57, 4135-4147. doi:10.1021/acs.biochem. $8 \mathrm{~b} 00603$

Chen, K., and Arnold, F. H. (2020). Engineering New Catalytic Activities in Enzymes. Nat. Catal. 3, 203-213. doi:10.1038/s41929-019-0385-5

Cheng, F., Chen, X.-L., Li, M.-Y., Zhang, X.-J., Jia, D.-X., Wang, Y.-J., et al. (2020a). Creation of a Robust and R-Selective $\omega$-amine Transaminase for the Asymmetric Synthesis of Sitagliptin Intermediate on a Kilogram Scale. Enzyme Microb. Tech. 141, 109655. doi:10.1016/j.enzmictec. 2020.109655

Cheng, F., Chen, X.-L., Xiang, C., Liu, Z.-Q., Wang, Y.-J., and Zheng, Y.-G. (2020b). Fluorescence-based High-Throughput Screening System for R- $\omega$ Transaminase Engineering and its Substrate Scope Extension. Appl. Microbiol. Biotechnol. 104, 2999-3009. doi:10.1007/s00253-020-10444-y

\section{DATA AVAILABILITY STATEMENT}

The original contributions presented in the study are included in the article/Supplementary Material, further inquiries can be directed to the corresponding author.

\section{AUTHOR CONTRIBUTIONS}

AP: Experiment, methodology, data collection and analysis, writing original draft preparation. HJ, TK, SS, PG, LS: Methodology and experiment. TY and BK: review and editing, HY: Conceptualization, review and editing, project administration. All authors have read and agreed to the published version of the manuscript.

\section{FUNDING}

This research was supported by Konkuk University Researcher Fund (\#2018-A019-0193) in 2018.

\section{SUPPLEMENTARY MATERIAL}

The Supplementary Material for this article can be found online at: https://www.frontiersin.org/articles/10.3389/fchem.2022.839636/ full\#supplementary-material

Chin, J. W. (2017). Expanding and Reprogramming the Genetic Code. Nature 550, 53-60. doi:10.1038/nature24031

Chin, J. W. (2014). Expanding and Reprogramming the Genetic Code of Cells and Animals. Annu. Rev. Biochem. 83, 379-408. doi:10.1146/annurevbiochem-060713-035737

Chin, J. W., Martin, A. B., King, D. S., Wang, L., and Schultz, P. G. (2002). Addition of a Photocrosslinking Amino Acid to the Genetic Code of Escherichia coli. Proc. Natl. Acad. Sci. 99, 11020-11024. doi:10.1073/ pnas.172226299

Dai, Y.-N., Chi, C.-B., Zhou, K., Cheng, W., Jiang, Y.-L., Ren, Y.-M., et al. (2013). Structure and Catalytic Mechanism of Yeast 4-Amino-4-Deoxychorismate Lyase. J. Biol. Chem. 288, 22985-22992. doi:10.1074/jbc.M113.480335

Dawood, A. W. H., Bassut, J., de Souza, R. O. M. A., and Bornscheuer, U. T. (2018). Combination of the Suzuki-Miyaura Cross-Coupling Reaction with Engineered Transaminases. Chem. Eur. J. 24, 16009-16013. doi:10.1002/chem.201804366

Deepankumar, K., Shon, M., Nadarajan, S. P., Shin, G., Mathew, S., Ayyadurai, N., et al. (2014). Enhancing Thermostability and Organic Solvent Tolerance of $\omega$ Transaminase through Global Incorporation of Fluorotyrosine. Adv. Synth. Catal. 356, 993-998. doi:10.1002/adsc.201300706

D. Patil, M., Grogan, G., Bommarius, A., and Yun, H. (2018). Recent Advances in $\omega$-Transaminase-Mediated Biocatalysis for the Enantioselective Synthesis of Chiral Amines. Catalysts 8, 254. doi:10.3390/catal8070254

Drienovská, I., Gajdoš, M., Kindler, A., Takhtehchian, M., Darnhofer, B., BirnerGruenberger, R., et al. (2020). Folding Assessment of Incorporation of Noncanonical Amino Acids Facilitates Expansion of Functional-Group Diversity for Enzyme Engineering. Chem. Eur. J. 26, 12338-12342. doi:10. 1002/chem.202002077

Drienovská, I., and Roelfes, G. (2020). Expanding the Enzyme Universe with Genetically Encoded Unnatural Amino Acids. Nat. Catal. 3, 193-202. doi:10. 1038/s41929-019-0410-8 
Exner, M. P., Kuenzl, T., To, T. M. T., Ouyang, Z., Schwagerus, S., Hoesl, M. G., et al. (2017). Design ofS-Allylcysteine In Situ Production and Incorporation Based on a Novel Pyrrolysyl-tRNA Synthetase Variant. ChemBioChem 18, 85-90. doi:10.1002/cbic.201600537

Ferrandi, E. E., and Monti, D. (2018). Amine Transaminases in Chiral Amines Synthesis: Recent Advances and Challenges. World J. Microbiol. Biotechnol. 34, 1-10. doi:10.1007/s11274-017-2395-2

Fuchs, M., Farnberger, J. E., and Kroutil, W. (20152015). The Industrial Age of Biocatalytic Transamination. Eur. J. Org. Chem. 2015, 6965-6982. doi:10.1002/ ejoc. 201500852

Gao, S., Su, Y., Zhao, L., Li, G., and Zheng, G. (2017). Characterization of a (R)selective Amine Transaminase from Fusarium Oxysporum. Process Biochem. 63, 130-136. doi:10.1016/j.procbio.2017.08.012

Giri, P., Pagar, A. D., Patil, M. D., and Yun, H. (2021). Chemical Modification of Enzymes to Improve Biocatalytic Performance. Biotechnol. Adv. 53, 107868. doi:10.1016/j.biotechadv.2021.107868

Green, A. P., Hayashi, T., Mittl, P. R. E., and Hilvert, D. (2016). A Chemically Programmed Proximal Ligand Enhances the Catalytic Properties of a Heme Enzyme. J. Am. Chem. Soc. 138, 11344-11352. doi:10.1021/jacs.6b07029

Guan, L.-J., Ohtsuka, J., Okai, M., Miyakawa, T., Mase, T., Zhi, Y., et al. (2015). A New Target Region for Changing the Substrate Specificity of Amine Transaminases. Sci. Rep. 5, 1-8. doi:10.1038/srep10753

Guo, F., and Berglund, P. (2017). Transaminase Biocatalysis: Optimization and Application. Green. Chem. 19, 333-360. doi:10.1039/c6gc02328b

Han, S.-W., Kim, J., Cho, H.-S., and Shin, J.-S. (2017). Active Site Engineering of $\omega$ Transaminase Guided by Docking Orientation Analysis and Virtual Activity Screening. ACS Catal. 7, 3752-3762. doi:10.1021/acscatal.6b03242

Hoesl, M. G., Acevedo-Rocha, C. G., Nehring, S., Royter, M., Wolschner, C., Wiltschi, B., et al. (2011). Lipase Congeners Designed by Genetic Code Engineering. ChemCatChem 3, 213-221. doi:10.1002/cctc.201000253

Höhne, M., Schätzle, S., Jochens, H., Robins, K., and Bornscheuer, U. T. (2010). Rational Assignment of Key Motifs for Function Guides In Silico Enzyme Identification. Nat. Chem. Biol. 6, 807-813. doi:10.1038/ nchembio. 447

Hou, A., Deng, Z., Ma, H., and Liu, T. (2016). Substrate Screening of Amino Transaminase for the Synthesis of a Sitagliptin Intermediate. Tetrahedron 72, 4660-4664. doi:10.1016/j.tet.2016.06.039

Iglesias, C., Panizza, P., and Rodriguez Giordano, S. (2017). Identification, Expression and Characterization of an R- $\omega$-Transaminase from Capronia Semiimmersa. Appl. Microbiol. Biotechnol. 101, 5677-5687. doi:10.1007/ s00253-017-8309-2

Italia, J. S., Addy, P. S., Erickson, S. B., Peeler, J. C., Weerapana, E., and Chatterjee, A. (2019). Mutually Orthogonal Nonsense-Suppression Systems and Conjugation Chemistries for Precise Protein Labeling at up to Three Distinct Sites. J. Am. Chem. Soc. 141, 6204-6212. doi:10.1021/jacs. 8 b12954

Iwasaki, A., Matsumoto, K., Hasegawa, J., and Yasohara, Y. (2012). A Novel Transaminase, (R)-amine:pyruvate Aminotransferase, from Arthrobacter Sp. KNK168 (FERM BP-5228): Purification, Characterization, and Gene Cloning. Appl. Microbiol. Biotechnol. 93, 1563-1573. doi:10.1007/s00253-011-3580-0

Iwasaki, A., Yamada, Y., Kizaki, N., Ikenaka, Y., and Hasegawa, J. (2006). Microbial Synthesis of Chiral Amines by (R)-specific Transamination with Arthrobacter Sp. KNK168. Appl. Microbiol. Biotechnol. 69, 499-505. doi:10.1007/s00253005-0002-1

Jackson, J. C., Duffy, S. P., Hess, K. R., and Mehl, R. A. (2006). Improving Nature's Enzyme Active Site with Genetically Encoded Unnatural Amino Acids. J. Am. Chem. Soc. 128, 11124-11127. doi:10.1021/ja061099y

Jackson, J. C., Hammill, J. T., and Mehl, R. A. (2007). Site-specific Incorporation of a 19F-Amino Acid into Proteins as an NMR Probe for Characterizing Protein Structure and Reactivity. J. Am. Chem. Soc. 129, 1160-1166. doi:10.1021/ ja064661t

Kelly, S. A., Mix, S., Moody, T. S., and Gilmore, B. F. (2020). Transaminases for Industrial Biocatalysis: Novel Enzyme Discovery. Appl. Microbiol. Biotechnol. 104, 4781-4794. doi:10.1007/s00253-020-10585-0

Kelly, S. A., Pohle, S., Wharry, S., Mix, S., Allen, C. C. R., Moody, T. S., et al. (2018). Application of $\omega$-Transaminases in the Pharmaceutical Industry. Chem. Rev. 118, 349-367. doi:10.1021/acs.chemrev.7b00437
Kim, S., Sung, B. H., Kim, S. C., and Lee, H. S. (2018). Genetic Incorporation OflDihydroxyphenylalanine (DOPA) Biosynthesized by a Tyrosine Phenol-Lyase. Chem. Commun. 54, 3002-3005. doi:10.1039/c8cc00281a

Koch, N. G., Goettig, P., Rappsilber, J., and Budisa, N. (2021). Engineering Pyrrolysyl-Trna Synthetase for the Incorporation of Non-canonical Amino Acids with Smaller Side Chains. Ijms 22, 11194. doi:10.3390/ijms222011194

Kolev, J. N., Zaengle, J. M., Ravikumar, R., and Fasan, R. (2014). Enhancing the Efficiency and Regioselectivity of P450 Oxidation Catalysts by Unnatural Amino Acid Mutagenesis. ChemBioChem 15, 1001-1010.

Konia, E., Chatzicharalampous, K., Drakonaki, A., Muenke, C., Ermler, U., Tsiotis, G., et al. (2021). Rational Engineering of Luminiphilus Syltensis (R)-selective Amine Transaminase for the Acceptance of Bulky Substrates. Chem. Commun. 57, 12948-12951. doi:10.1039/d1cc04664k

Lakó, Á., Molnár, Z., Mendonça, R., and Poppe, L. (2020). Transaminase-mediated Synthesis of Enantiopure Drug-like 1-(3',4'-disubstituted Phenyl)propan-2Amines. RSC Adv. 10, 40894-40903. doi:10.1039/d0ra08134e

Lee, B. S., Choi, W. J., Lee, S. W., Ko, B. J., and Yoo, T. H. (2021). Towards Engineering an Orthogonal Protein Translation Initiation System. Front. Chem. 9, 1-9. doi:10.3389/fchem.2021.772648

Lee, Y.-J., Schmidt, M. J., Tharp, J. M., Weber, A., Koenig, A. L., Zheng, H., et al. (2016). Genetically Encoded Fluorophenylalanines Enable Insights into the Recognition of Lysine Trimethylation by an Epigenetic Reader. Chem. Commun. 52, 12606-12609. doi:10.1039/c6cc05959g

Liu, C.-Y., Cecylia Severin, L., Lyu, C.-J., Zhu, W.-L., Wang, H.-P., Jiang, C.-J., et al. (2021). Improving Thermostability of (R)-selective Amine Transaminase from Aspergillus terreus by Evolutionary Coupling Saturation Mutagenesis. Biochem. Eng. J. 167, 107926. doi:10.1016/j.bej.2021.107926

Łyskowski, A., Gruber, C., Steinkellner, G., Schürmann, M., Schwab, H., Gruber, K., et al. (2014). Crystal Structure of an (R)-Selective $\omega$ Transaminase from Aspergillus terreus. PLoS One 9, e87350. doi:10. 1371/journal.pone. 0087350

Ma, Y., Biava, H., Contestabile, R., Budisa, N., and Di Salvo, M. (2014). Coupling Bioorthogonal Chemistries with Artificial Metabolism: Intracellular Biosynthesis of Azidohomoalanine and its Incorporation into Recombinant Proteins. Molecules 19, 1004-1022. doi:10.3390/molecules19011004

Mathew, S., Deepankumar, K., Shin, G., Hong, E. Y., Kim, B.-G., Chung, T., et al. (2016). Identification of Novel Thermostable $\omega$-transaminase and its Application for Enzymatic Synthesis of Chiral Amines at High Temperature. RSC Adv. 6, 69257-69260. doi:10.1039/c6ra15110h

Mathew, S., and Yun, H. (2012). $\omega$-Transaminases for the Production of Optically Pure Amines and Unnatural Amino Acids. ACS Catal. 2, 993-1001. doi:10. $1021 / \mathrm{cs} 300116 \mathrm{n}$

Miyake-Stoner, S. J., Refakis, C. A., Hammill, J. T., Lusic, H., Hazen, J. L., Deiters, A., et al. (2010). Generating Permissive Site-specific Unnatural AminoacyltRNA Synthetases. Biochemistry 49, 1667-1677. doi:10.1021/bi901947r

Neumann, H., Wang, K., Davis, L., Garcia-Alai, M., and Chin, J. W. (2010). Encoding Multiple Unnatural Amino Acids via Evolution of a QuadrupletDecoding Ribosome. Nature 464, 441-444. doi:10.1038/nature08817

Nojoumi, S., Ma, Y., Schwagerus, S., Hackenberger, C. P. R., and Budisa, N. (2019). In-cell Synthesis of Bioorthogonal Alkene Tag S-Allyl-Homocysteine and its Coupling with Reprogrammed Translation. Ijms 20, 2299. doi:10.3390/ ijms20092299

Ohtake, K., Mukai, T., Iraha, F., Takahashi, M., Haruna, K.-i., Date, M., et al. (2018). Engineering an Automaturing Transglutaminase with Enhanced Thermostability by Genetic Code Expansion with Two Codon Reassignments. ACS Synth. Biol. 7, 2170-2176. doi:10.1021/acssynbio.8b00157

Pagar, A. D., Patil, M. D., Flood, D. T., Yoo, T. H., Dawson, P. E., and Yun, H. (2021). Recent Advances in Biocatalysis with Chemical Modification and Expanded Amino Acid Alphabet. Chem. Rev. 121, 6173-6245. doi:10.1021/ acs.chemrev.0c01201

Pan, X., Yang, J., Xie, P., Zhang, J., Ke, F., Guo, X., et al. (2021). Enhancement of Activity and Thermostability of Keratinase from Pseudomonas aeruginosa CCTCC AB2013184 by Directed Evolution with Noncanonical Amino Acids. Front. Bioeng. Biotechnol. 9, 1-15. doi:10.3389/fbioe.2021.770907

Park, J., Lee, Y., Ko, B. J., and Yoo, T. H. (2018). Peptide-Directed Photo-CrossLinking for Site-specific Conjugation of IgG. Bioconjug. Chem. 29, 3240-3244. doi:10.1021/acs.bioconjchem.8b00515 
Pavkov-Keller, T., Strohmeier, G. A., Diepold, M., Peeters, W., Smeets, N., Schürmann, M., et al. (2016). Discovery and Structural Characterisation of New Fold Type IV-Transaminases Exemplify the Diversity of This Enzyme Fold. Sci. Rep. 6, 1-12. doi:10.1038/srep38183

Qu, G., Li, A., Acevedo-Rocha, C. G., Sun, Z., and Reetz, M. T. (2020). The Crucial Role of Methodology Development in Directed Evolution of Selective Enzymes. Angew. Chem. Int. Ed. 59, 13204-13231. doi:10.1002/anie.201901491

Rocha, J. F., Pina, A. F., Sousa, S. F., and Cerqueira, N. M. F. S. A. (2019). PLPdependent Enzymes as Important Biocatalysts for the Pharmaceutical, Chemical and Food Industries: A Structural and Mechanistic Perspective. Catal. Sci. Technol. 9, 4864-4876. doi:10.1039/c9cy01210a

Sarak, S., Sung, S., Jeon, H., Patil, M. D., Khobragade, T. P., Pagar, A. D., et al. (2021). An Integrated Cofactor/Co-Product Recycling Cascade for the Biosynthesis of Nylon Monomers from Cycloalkylamines. Angew. Chem. Int. Ed. 60, 3481-3486. doi:10.1002/anie.202012658

Savile, C. K., Janey, J. M., Mundorff, E. C., Moore, J. C., Tam, S., Jarvis, W. R., et al. (2010). Biocatalytic Asymmetric Synthesis of Chiral Amines from Ketones Applied to Sitagliptin Manufacture. Science 329, 305-309. doi:10.1126/science.1188934

Sayer, C., Martinez-Torres, R. J., Richter, N., Isupov, M. N., Hailes, H. C., Littlechild, J. A., et al. (2014). The Substrate Specificity, Enantioselectivity and Structure of the (R)-selective Amine : Pyruvate Transaminase fromNectria Haematococca. FEBS J. 281, 2240-2253. doi:10.1111/febs.12778

Schätzle, S., Steffen-Munsberg, F., Thontowi, A., Höhne, M., Robins, K., and Bornscheuer, U. T. (2011). Enzymatic Asymmetric Synthesis of Enantiomerically Pure Aliphatic, Aromatic and Arylaliphatic Amines with (R)-selective Amine Transaminases. Adv. Synth. Catal. 353, 2439-2445. doi:10.1002/adsc.201100435

Schipp, C. J., Ma, Y., Al-Shameri, A., D’Alessio, F., Neubauer, P., Contestabile, R., et al. (2020). An Engineered Escherichia coli Strain with Synthetic Metabolism for in-Cell Production of Translationally Active Methionine Derivatives. ChemBioChem 21, 3525-3538. doi:10.1002/cbic.202000257

Shin, G., Mathew, S., and Yun, H. (2015). Kinetic Resolution of Amines by (R)selective omega-transaminase from Mycobacterium Vanbaalenii. J. Ind. Eng. Chem. 23, 128-133. doi:10.1016/j.jiec.2014.08.003

Siddiqui, K. S. (2017). Defying the Activity-Stability Trade-Off in Enzymes: Taking Advantage of Entropy to Enhance Activity and Thermostability. Crit. Rev. Biotechnol. 37, 309-322. doi:10.3109/07388551.2016.1144045

Slabu, I., GalmanLloyd, J. L, Richard, C. A., Lloyd, R. C., and Turner, N. J. (2017). Discovery, Engineering, and Synthetic Application of Transaminase Biocatalysts. ACS Catal. 7, 8263-8284. doi:10.1021/acscatal.7b02686

Steffen-Munsberg, F., Vickers, C., Kohls, H., Land, H., Mallin, H., Nobili, A., et al. (2015). Bioinformatic Analysis of a PLP-dependent Enzyme Superfamily Suitable for Biocatalytic Applications. Biotechnol. Adv. 33, 566-604. doi:10. 1016/j.biotechadv.2014.12.012

Telzerow, A., Paris, J., Håkansson, M., González-Sabín, J., Ríos-Lombardía, N., Gröger, H., et al. (2021). Expanding the Toolbox of R -Selective Amine Transaminases by Identification and Characterization of New Members. ChemBioChem 22, 1232-1242. doi:10.1002/cbic.202000692

Telzerow, A., Paris, J., Håkansson, M., González-Sabín, J., Ríos-Lombardía, N., Schürmann, M., et al. (2019). Amine Transaminase from Exophiala Xenobiotica-Crystal Structure and Engineering of a Fold IV Transaminase that Naturally Converts Biaryl Ketones. ACS Catal. 9, 1140-1148. doi:10.1021/ acscatal.8b04524

Tseng, H.-W., Baumann, T., Sun, H., Wang, Y.-S., Ignatova, Z., and Budisa, N. (2020). Expanding the Scope of Orthogonal Translation with Pyrrolysyl-tRNA
Synthetases Dedicated to Aromatic Amino Acids. Molecules 25, 4418-18. doi:10.3390/molecules25194418

Voss, M., Xiang, C., Esque, J., Nobili, A., Menke, M. J., André, I., et al. (2020). Creation of (R)-Amine Transaminase Activity within an a-Amino Acid Transaminase Scaffold. ACS Chem. Biol. 15, 416-424. doi:10.1021/ acschembio.9b00888

Wang, L., and Schultz, P. G. (2005). Expanding the Genetic Code. Angew. Chem. Int. Ed. 44, 34-66. doi:10.1002/anie.200460627

Wang, Y., Xue, P., Cao, M., Yu, T., Lane, S. T., and Zhao, H. (2021). Directed Evolution: Methodologies and Applications. Chem. Rev. 121, 12384-12444. doi:10.1021/acs.chemrev.1c00260

Won, Y., Jeon, H., Pagar, A. D., Patil, M. D., Nadarajan, S. P., Flood, D. T., et al. (2019a). In Vivo biosynthesis of Tyrosine Analogs and Their Concurrent Incorporation into a Residue-specific Manner for Enzyme Engineering. Chem. Commun. 55, 15133-15136. doi:10.1039/c9cc08503c

Won, Y., Pagar, A. D., Patil, M. D., Dawson, P. E., and Yun, H. (2019b). Recent Advances in Enzyme Engineering through Incorporation of Unnatural Amino Acids. Biotechnol. Bioproc. E 24, 592-604. doi:10.1007/s12257-0190163-x

Young, D. D., and Schultz, P. G. (2018). Playing with the Molecules of Life. ACS Chem. Biol. 13, 854-870. doi:10.1021/acschembio.7b00974

Yu, H., and Dalby, P. A. (2018). Exploiting Correlated Molecular-Dynamics Networks to Counteract Enzyme Activity-Stability Trade-Off. Proc. Natl. Acad. Sci. USA 115, E12192-E12200. doi:10.1073/pnas.1812204115

Yu, Y., Hu, C., Xia, L., and Wang, J. (2018). Artificial Metalloenzyme Design with Unnatural Amino Acids and Non-native Cofactors. ACS Catal. 8, 1851-1863. doi:10.1021/acscatal.7b03754

Yu, Z., Yu, H., Tang, H., Wang, Z., Wu, J., Yang, L., et al. (2021). Site-specifically Incorporated Non-Canonical Amino Acids into Pseudomonas alcaligenes Lipase to Hydrolyze L -menthol Propionate Among the Eight Isomers. Chem CatChem 13, 2691-2701. doi:10.1002/cctc.202100358

Zeifman, Y. S., Boyko, K. M., Nikolaeva, A. Y., Timofeev, V. I., Rakitina, T. V., Popov, V. O., et al. (2019). Functional Characterization of PLP Fold Type IV Transaminase with a Mixed Type of Activity from Haliangium Ochraceum. Biochim. Biophys. Acta (Bba) - Proteins Proteomics 1867, 575-585. doi:10.1016/ j.bbapap.2019.03.005

Conflict of Interest: The authors declare that the research was conducted in the absence of any commercial or financial relationships that could be construed as a potential conflict of interest.

Publisher's Note: All claims expressed in this article are solely those of the authors and do not necessarily represent those of their affiliated organizations, or those of the publisher, the editors and the reviewers. Any product that may be evaluated in this article, or claim that may be made by its manufacturer, is not guaranteed or endorsed by the publisher.

Copyright (c) 2022 Pagar, Jeon, Khobragade, Sarak, Giri, Lim, Yoo, Ko and Yun. This is an open-access article distributed under the terms of the Creative Commons Attribution License (CC BY). The use, distribution or reproduction in other forums is permitted, provided the original author(s) and the copyright owner(s) are credited and that the original publication in this journal is cited, in accordance with accepted academic practice. No use, distribution or reproduction is permitted which does not comply with these terms. 